\title{
فT 477393 QA:NA 3/13/06 \\ Localized Corrosion Behavior of Type 304SS with a Silica Layer under Atmospheric Corrosion Environments
}

\author{
Eiji Tada*, Gerald S. Frankel \\ Fontana Corrosion Center, The Ohio State University \\ * Present address: Dept. Mater. Sci. \& Eng., Akita University
}

\section{Introduction}

The U.S. Department of Energy (DOE) has proposed a potential repository for spent nuclear fuel and high-level radioactive waste at the Yucca Mountain site in Nevada. [1] The temperature could be high on the waste packages, and it is possible that dripping water or humidity could interact with rock dust particulate to form a thin electrolyte layer with concentrated ionic species. Under these conditions, it is possible that highly corrosion-resistant alloys (CRAs) used as packages to dispose the nuclear waste could suffer localized corrosion. Therefore, to better understand long-term corrosion performance of CRAs in the repository, it is important to investigate localized corrosion under a simulated repository environment. We measured open circuit potential (OCP) and galvanic current $\left(i_{\mathrm{g}}\right.$ ) for silica-coated Type 304SS during drying of salt solutions under controlled $\mathrm{RH}$ environments to clarify the effect of silica layer as a dust layer simulant on localized corrosion under atmospheric environments. Type 304SS was used as a relatively susceptible model CRA instead of the much more corrosion resistant alloys, such as Alloy 22, that are being considered as waste package materials.

\section{Experimental}

Fig. 1 shows the electrochemical setup for the atmospheric corrosion experiments. A plastic container with a lid formed the chamber in which relative humidity was controlled using different saturated salt solutions, such as saturated $\mathrm{LiCl}$ and $\mathrm{MgCl}_{2}$. For a sample of OCP measurements, a plate of AISI 304 stainless steel (304SS, ca. $1 \mathrm{~cm} \times 1 \mathrm{~cm}$ ) was embedded in epoxy resin. The procedure of the OCP measurements was similar to that described by Vera Cruz et al. [2] For $i_{\mathrm{g}}$ measurements, two identical 304SS sheets (ca. $1 \mathrm{~cm} \mathrm{x} 0.2 \mathrm{~mm}$ ) were embedded in parallel with a gap of $0.23 \mathrm{~mm}$-thick plastic sheet in epoxy resin. The samples were polished with abrasive papers down to 1200 grit and cleaned ultrasonically with ethyl alcohol. Then electrophoretic deposition (EPD) was performed cathodically at a constant voltage of $29 \mathrm{~V}$ on the surface of 304SS from a suspension with silica particles obtained by a sol-gel method. The thickness of the silica layer was controlled up to ca. $60 \mu \mathrm{m}$ by varying the deposition time.

The test electrolyte solution used in this study was $0.5 \mathrm{M} \mathrm{MgCl}_{2}$. The initial thickness of the thin electrolyte layer was $500 \mu \mathrm{m}$. OCP transients for a silica-coated sample were measured 
during drying of the electrolyte in the $\mathrm{RH}$-controlled chamber. The reference electrode, $\mathrm{Ag} / \mathrm{AgCl}$ electrode in a $4 \mathrm{M} \mathrm{KCl}$ solution ( $\mathrm{SSE}, E_{\mathrm{SSE}}=0.197 \mathrm{~V}$ vs. SHE), was connected with a Luggin capillary. For $i_{\mathrm{g}}$ measurements, the current flowing between the pair of 304SS was measured during drying of the electrolyte by using a potentiostat set up as a zero-resistance ammeter.

\section{Results and discussion}

\subsection{Silica layer deposited by EPD}

Fig. 2a shows a photograph of a silica-coated 304SS. The silica layer formed on 304SS is a quite smooth and homogeneous coating. A SEM micrograph (Fig. 2b) reveals that the silica layer is composed of ca. $350 \mathrm{~nm}$ diameter spherical silica particles packed densely. When a drop of water was put at the edge of such a silica layer, the drop was absorbed rapidly into the silica. The whole surface became wet because of capillary action, with a contact angle of almost $0^{\circ}$. This hydrophilicity is the result of the hydrophilic characteristic of the silica particles and the open space between the mono-dispersed silica particles. After a wet silica layer was dried with air, the layer was found to be still intact. This result suggest that a silica layer deposited by EPD can work as if it were a humectant and that the layer can be used as a suitable host layer for a thin electrolyte layer under atmospheric conditions.

\subsection{OCP and $i_{\mathrm{g}}$ transients during drying of $\mathrm{MgCl}_{2}$}

Fig. 3 shows OCP transients for silica-coated and uncoated 304SS samples during drying of a thin layer of $0.5 \mathrm{M} \mathrm{MgCl}_{2}$ under conditions where the humidity was controlled by a reservoir of saturated $\mathrm{MgCl}_{2}$ or $\mathrm{LiCl}$ solution. The estimated thickness of the silica layers on the samples was about $17 \mu \mathrm{m}$. In the $\mathrm{MgCl}_{2}$ environment, the thin electrolyte layer will get thinner during drying, but stop decreasing in the thickness when the concentration of the electrolyte layer reaches the same concentration as the saturated $\mathrm{MgCl}_{2}$ reservoir. Because of the lower critical humidity for saturated $\mathrm{LiCl}$ solution, a thin layer of $\mathrm{MgCl}_{2}$ solution will eventually dry up. As shown in Fig. 3, pitting corrosion was initiated for all the samples as evidenced by an abrupt decrease in OCP to active potentials. Before pitting corrosion took place, the OCP transient for the silica-coated sample was almost the same as that for the uncoated sample during drying in the saturated $\mathrm{MgCl}_{2}$ environment. However the OCP transient for the silica-coated samples showed slower decay compared with the uncoated sample after pitting corrosion initiated. A similar trend was observed during drying in the saturated $\mathrm{LiCl}$ environment, although pitting corrosion initiated earlier due to the difference in drying rate. These results indicate that the silica layer might not influence pit initiation but might retard pit growth.

Fig. 4 shows $i_{\mathrm{g}}$ for a sample during drying of $0.5 \mathrm{M} \mathrm{MgCl}_{2}$ in a saturated $\mathrm{LiCl}$ environment. In this experiment, one of the two 304SS electrodes is coated with a silica layer of ca. $6 \mu \mathrm{m}$. As shown in Fig. 4, a current spike is seen at about $4.7 \mathrm{~h}$ due to initiation of pitting corrosion on the 
uncoated side. The current $i_{\mathrm{g}}$ increases slowly for only a while after initiation, suggesting that the pit growth might be impeded by the silica layer. After the peak current, stifling of pit growth is likely to take place during drying.

\section{Summary}

A silica layer deposited cathodically on 304SS absorbed electrolytes very well and it was utilized as a simulated dust layer to investigate localized corrosion behavior for CRAs under a simulated repository environments. In the course of drying, the OCP transient for silica-coated 304SS is similar to that for uncoated 304SS before initiation of pitting corrosion, but after initiation the OCP transient decays slower compared to the uncoated 304SS. This result suggests that the silica layer does not affect the initiation of pitting corrosion, but retards the propagation of pitting corrosion.

\section{Acknowledgments}

The support of this work from the Office of Science and Technology and International (OST\&I), Office of Civilian Radioactive Waste Management (OCRWM), U.S. Department of Energy (DOE) is gratefully acknowledged. The work is carried out as part of the DOE Multi-University Corrosion Cooperative under Cooperative Agreement DE-FC28-04RW12252.

The views, opinions, findings, and conclusions or recommendations of authors expressed herein do not necessarily state or reflect those of the DOE/OCRWM/OST\&I.

\section{Reference}

1. V. Desai, JOM, 18, (2005) p. 18.

2. R. P. Vera Cruz, A. Nishikata, and T. Tsuru, Corros. Sci., 40, 125 (1998). 


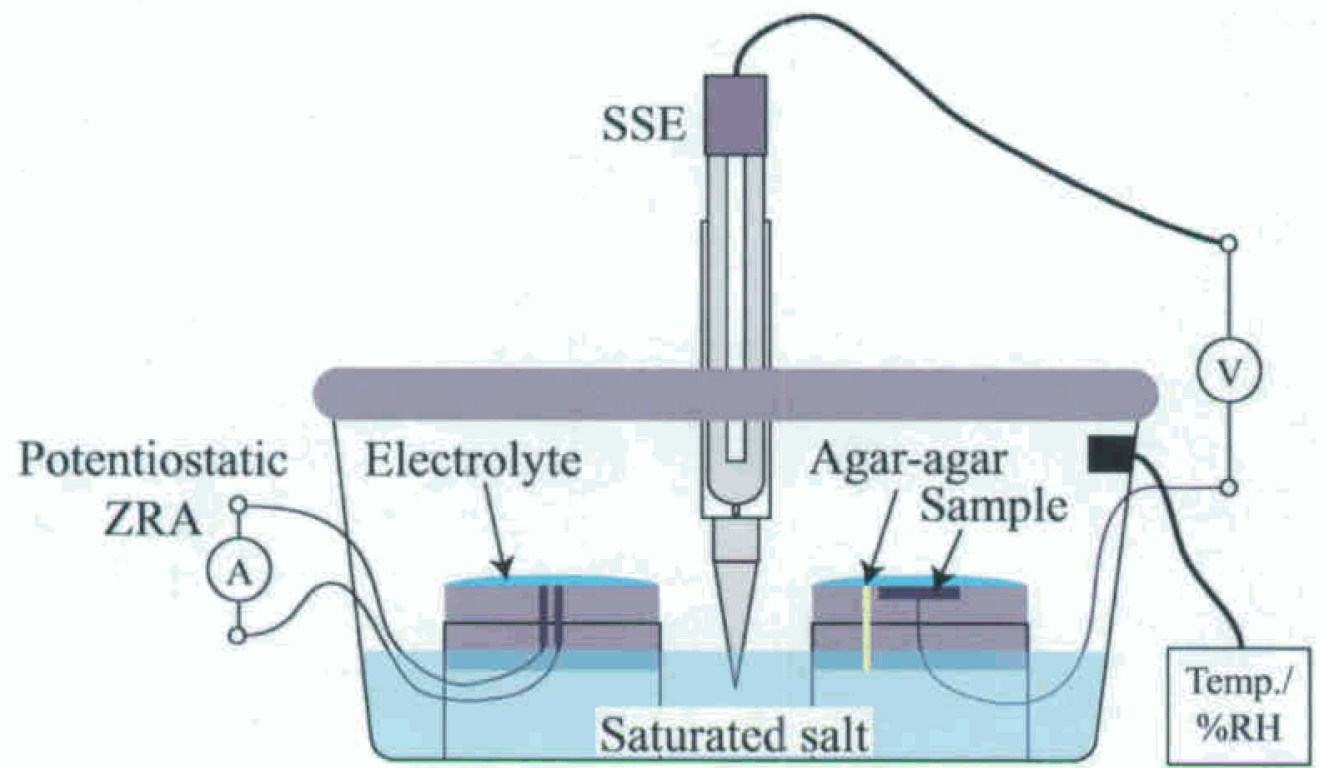

Figure 1. Electrochemical setup for OCP and $i_{\mathrm{g}}$ measurements of silica-coated samples under atmospheric corrosion environments. 

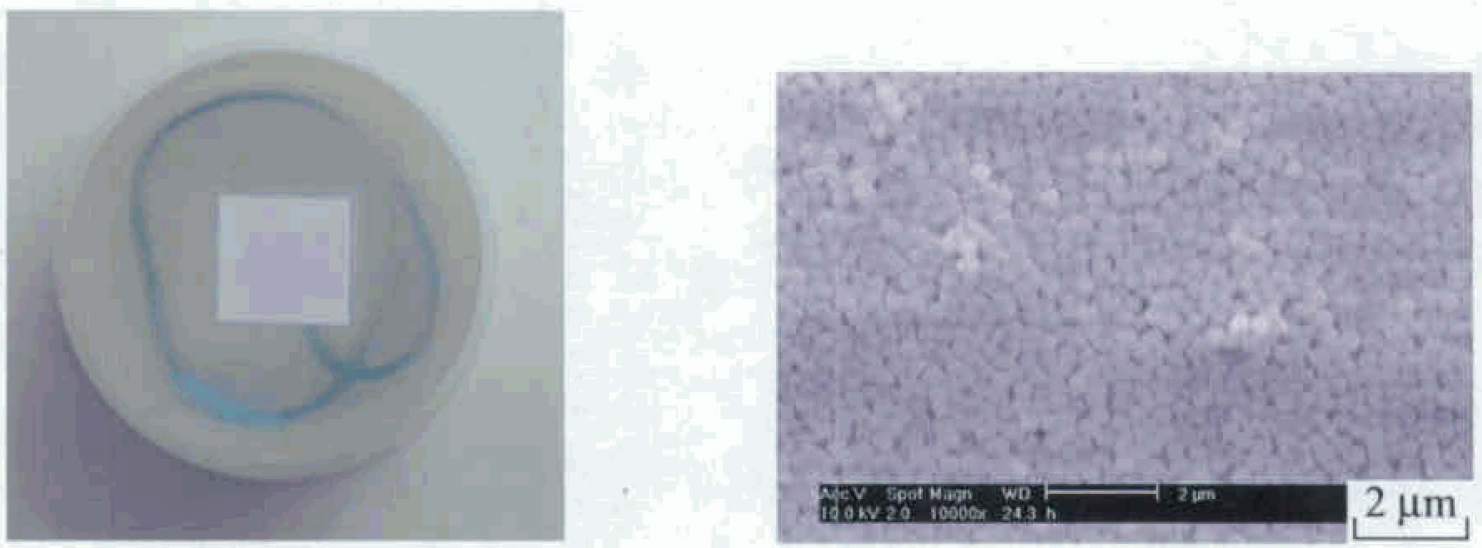

Figure 2. Photographs of the surface of a silica layer obtained by cathodic EPD for $5 \mathrm{~s}$.

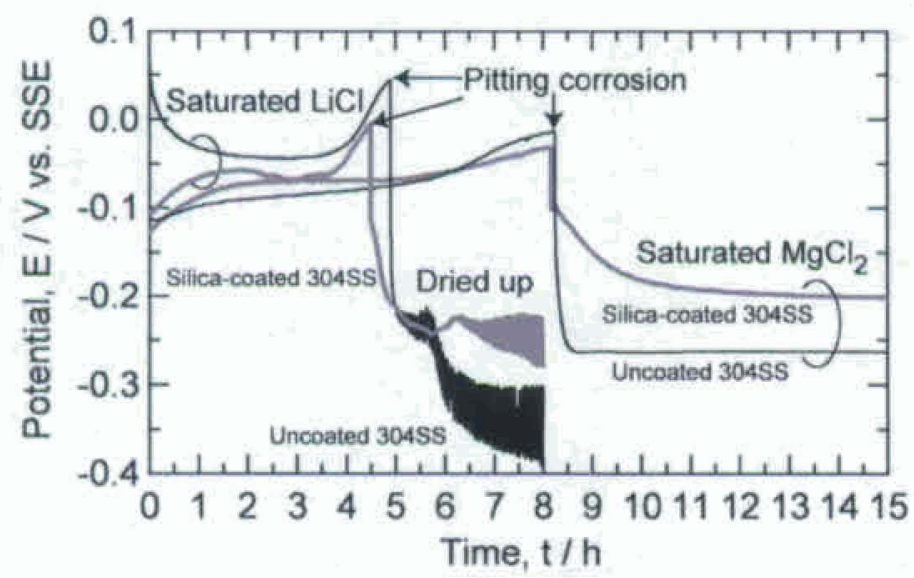

Figure 3. OCP transients for silica-coated and uncoated samples in saturated $\mathrm{MgCl}_{2}$ and $\mathrm{LiCl}$ environment.

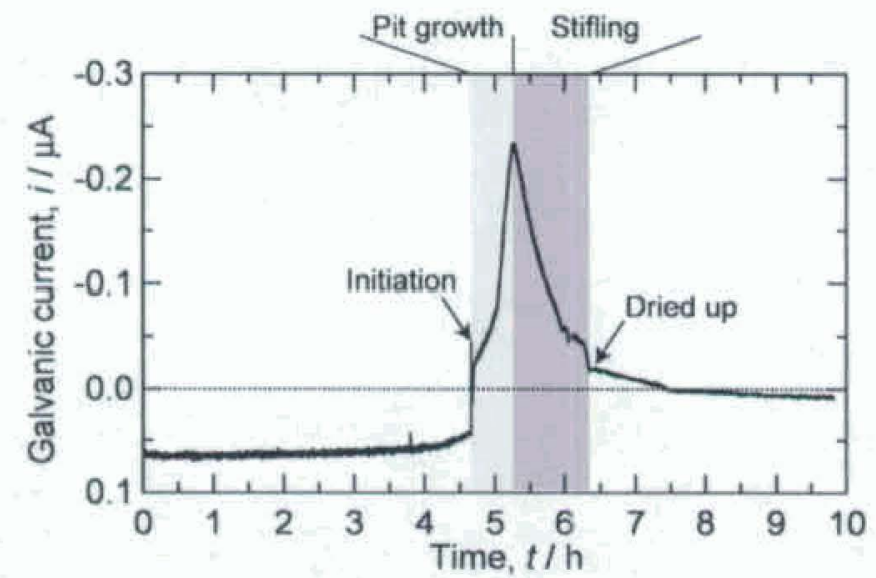

Figure 4. $\quad i_{\mathrm{g}}$ transients for a silica-coated samples under saturated $\mathrm{LiCl}$ environment. 